\title{
POSITIONS AND ACTIONS OF CLASSROOM-SPECIFIC APPLAUSE
}

\author{
Yuri Hosoda and David Aline
}

\begin{abstract}
While the interactional conditions and timing of applause in audience response to public speeches has received attention in conversation analysis research, little research has been done on applause in educational contexts. The nature of applause, however, can vary depending on the context. This paper examines classroom-specific applause and focuses on where in classroom interaction the applause can occur, who initiates the applause, and what the applause accomplishes in the interaction. The data come from 14 audio and video-recorded Japanese primary school EFL class sessions. The analysis reveals that the applause in the data was a typically teacher-initiated action and it regularly occurred in sequence closing position as a positive assessment to the students' success in carrying out the teachers' oriented-to expectations.
\end{abstract}

Keywords: EFL classroom; Conversation analysis; Applause; Classroom interaction; Primary school.

\section{Introduction}

Unlike talk in ordinary conversation, applause is one of the several activities that have a preference to be done together with others. While talking in conversation is designed to be done one at a time (Sacks, Schegloff, \& Jefferson 1974), some activities such as laughter, choral music and repetition, and applause are designed to be done or can be done at the same time with others rather than alone. We must note, however, that in spite of its simultaneity, the occurrence of those activities is as orderly as talking. For example, Jefferson (1985) and Jefferson, Sacks, and Schegloff (1987) demonstrated how systematically laughter occurs in relation to talk.

The interactional phenomenon of applause has also received some attention, particularly in the conversation analysis (CA) literature. For instance, Atkinson (1984a, 1984b, 1985, 1986) examined political speeches and analyzed the how, when, and what of audience applause. Specifically, he discovered that applause is an affiliative reaction to techniques (i.e., certain kinds of rhetorical constructions) used by the public speaker which aid the audience in understanding when it is permissible for them to participate in this type of institutional interaction. Heritage and Greatbatch (1986) conducted further research on applause in political speeches and examined Atkinson's findings concerning the role of rhetorical devices in the generation of applause. To date, research on the interactional use of applause has been limited to analysis of political speeches.

While conducting observational research on English as a foreign language (EFL) classes in Japanese primary (elementary) schools, our attention was drawn to the significant amount of applause throughout the interaction. The applause was different from the affiliative applause of the previously cited studies as it was not applause invited by the speaker (usually a student called on to provide a response), but was typically initiated by the teacher. In political speeches the speaker signals the audience as to when it is permissible for them to take a turn, in the form of applause, through 
rhetorical techniques. In the institutional setting of the classroom, however, the teacher, acting as audience to the student speaking, appears to control the applause, but it remains to be demonstrated how applause is distributed and what applause accomplishes in the unfolding interaction.

This study investigates the deployment of applause by teachers teaching English as a foreign language in Japanese primary school English Activities ${ }^{1}$ classes. Viewing the interaction of the teacher and students through the methodological lens of conversation analysis, the data disclosed where applause occurs, who initiates applause, and what applause accomplishes in the interaction. In the course of the analysis, the teacher and student orientation to applause will be revealed. In this study, we do not state the results in advance as we do not want to influence the analysis of the data by the reader. If our findings are valid, the reader should be able to come to the same conclusions through the same analysis. Consequently, our findings are presented in the conclusion.

What constitutes applause in this paper are the clapping behaviors that occur in the specific sequential position in the classroom interaction, as described in the subsequent sections, namely the clapping behaviors in third position ${ }^{2}$ following student response to teacher initiations. This definition slightly differs from that used in previously cited studies which analyzed political speeches. Atkinson (1984b) defines applause as an audience display of affiliation in response to something said by a speaker and notes that clapping can only become applause when several people do so simultaneously. In this paper, however, we do not judge whether the instance is applause or not a priori to the analysis based on the number of people clapping. That is to say, when the clapping is not joined by others, if the clapping performs affiliative actions, the instance is treated as applause. For example, when clapping was done by the teacher in the third position, even when it is not joined by others, it demonstrated affiliative action and thus we refer to these instances as applause.

\section{The study}

Following an overview of the methodology used for analysis of the data, we describe the occurrence of applause in terms of where applause happens in the interaction and who initiates applause. We then explicate what applause does in the interaction. The paper concludes with a discussion of how the findings relate to second language pedagogy and learning.

\section{Method}

The data for this study come from 10 audio and video-recorded Japanese primary school EFL class sessions, approximately 10 hours in total of class time. The schools were randomly selected from throughout Japan, and were visited during the 2004 to 2006 academic years as part of a nation-wide research project observing the newly instituted Japanese curriculum, which introduced EFL classes in the form of English activities to primary schools (JSPS Grant No. 16520359). In Japan, children attend primary school for six years, starting from the age of seven, and class sizes vary between urban and rural areas.

For this study, classes from all grade levels were observed and recorded. They

1 The term "English Activities" is used to refer to language classes in which the students are exposed to a second language through games, songs, and other activities as opposed to studying about the language itself.

${ }^{2}$ The term "third position" refers to the sequential position that analyzably follows student response to teacher initiation. This may or may not appear in the third turn depending on occurrence of insertion sequences between the student response and teacher reaction to the response. 
ranged in size from 12 to 42 students, with an average size of 30 . However, as shown in the analysis section, no differences were found in occurrence of applause due to grade level or class size in this data set. Moreover, although the gender of the teachers varied for both visiting teachers and Japanese teachers, no differences in deployment of teacher-initiated applause were found for gender.

The classes in this study were taught by visiting teachers who are native speakers of English and conduct English Activities classes at many schools in one school district. While the visiting teacher acted as the main teacher and almost always initiated the main sequences of the classroom interaction, there was always a certified Japanese homeroom teacher in the room as required by Japanese law. The other four classes were taught only by Japanese teachers.

All interaction in these classes was transcribed using the Jeffersonian transcription system, which is commonly used in conversation analysis (Jefferson 1984) (see Appendix for transcription conventions used in this study). We then analyzed the transcript and the original video recordings in an "unmotivated way" (Sacks 1984: 27) so as not to project any a priori assumptions onto the data. The researchers began the research project with no preconceived research questions or hypotheses in mind, and made a variety of observations. As a result of the analyses, our attention was drawn to the unique occurrence of teacher-initiated applause in the interaction. From this data set, over 100 instances of teacher-initiated applause were observed.

\section{Occurrence of applause}

In order to identify the patterns of applause in the English classes, we first examined the interactional context in which applause occurred; specifically, we analyzed all of the data for where in the interaction sequences applause occurred and who initiated the applause.

\section{Where applause occurs}

Examination of applause sequences revealed that applause occurred in the following two kinds of sequential closing environments: (a) at the place where one teaching activity ended and before a new activity started; and (b) at the place where a sequence between the teacher and a student or between students ended and before a new sequence between the teacher and the next student or students began. In both cases, applause occurred in overlap with the teacher's verbal tokens, "good," "very good," "okay," or some variation thereof. ${ }^{3}$

Shown in Extract (1) is an example of applause occurring at a place where one teaching activity ended and before a new activity started. In the extracts below, VT refers to a visiting teacher, JT refers to a regular Japanese homeroom teacher, S refers to a student, and Ss refers to choral responses by the students . (In Extracts (1), (6), and (7), the visiting teacher is the same person. In all other extracts, each visiting teacher, Japanese homeroom teacher, or student is a different person.)

(1) [Nagano3:7:01-11]

01 VT: how's the: wea:ther::

02 Ss: ((laugh)) i(h)t's ra(h)iny::.

03 VT: how::

04 Ss: ((laugh))

3 The occurrence of verbal tokens such as "good" and "okay" is not specific to classroom contexts. In ordinary conversations, such tokens have also been found to occur at the sequence closing positions to terminate a sequence (Goodwin 1986; Schegloff 2007). 


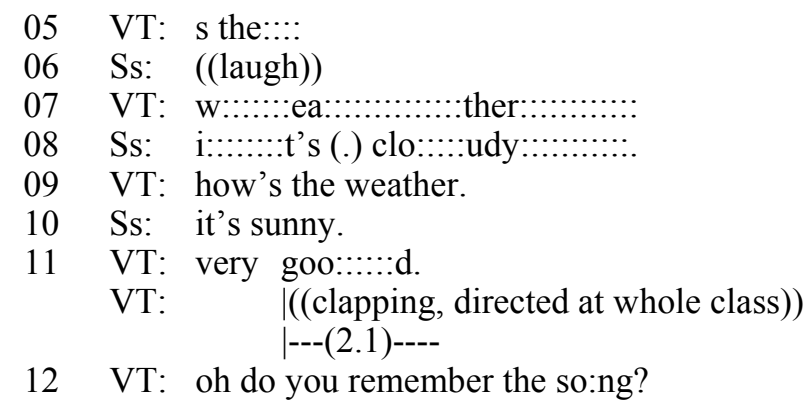

In the interaction shown in Extract (1), from lines 1 to 10, the class is practicing how to ask and answer questions about the weather. After numerous repetitions of the teacher asking "how's the weather?" and the students answering according to which card depicting various types of weather the teacher points to, the teacher, in line 9 , points out the window to that day's actual weather and asks, "how's the weather?" The students respond to this question in line 10 with the correct adjective for that day's weather, "it's sunny." In line 11, the teacher closes the activity by saying "very goo::::::d" and clapping her hands in overlap with the prolonged "goo::::::d". After clapping her hands for 2.1 seconds, she introduces the next language learning activity, singing a song that the students had previously learned.

Extract (2) is an example of applause that occurred at a place where a sequence between the teacher and a student came to a conclusion. The instructional focus for the lesson was on the lexical phrase for asking about location of an object, "Where is the...?", and the use of the prepositions "in," "on," and "under," to give the answer to express the location of the object. Prior to the interaction shown in Extract (2), one student, S1, volunteered to participate in a public language display with the teacher by answering a question about location. Consequently, the visiting teacher (VT) placed a stuffed toy dog on a chair as a referent for the language learning activity.

(2) [Tokyo: 04:06-13]

01 VT: where is the dog?

02 JT: $\left[{ }^{\circ}\right.$ it's on ${ }^{\circ}$

03 VT: [( )?

04 JT: ${ }^{\circ}\left[t^{\prime}\right.$ 's on ${ }^{\circ}$

05 VT: $\quad\left[{ }^{\circ}\right.$ it's on ${ }^{\circ}$

06 S1: [it's o::n the dog ah chair.

07 (VT/JT): goo:[:::|::d. oka::y.

(VT/JT): $\quad \mid($ clapping $)$

$08 \quad$ (JT/VT): $\quad$ [goo:|:-:|:d

(JT/VT): $\quad$ ((clapping))

|--(2.5)----

Ss: $\quad \mid(($ clapping $))$

09 VT: [anybody else?

|---(3.0)-----

10 S2: [((raises a hand $))$

The visiting teacher, in line 1, asks S1 the display question, "where is the dog?" With the whispered assistance of the visiting teacher and the Japanese homeroom teacher (JT), S1 starts to answer the question with the correct form in line 6, "it's on the ..." However, she initially produces the referent from the question, "dog", and then self-corrects with the appropriate noun for the location, "chair". Then in line 7, the visiting teacher or the Japanese teacher (it is difficult even with the video to determine which because their voices are so similar) produces "good" and starts clapping her hands for a period of 2.1 
seconds. The two teachers produce "goo::::d" in overlap, one starting just before the other, and then the entire class starts applauding (all except for S1). The applause continues for a total of 3 seconds. Immediately following the end of the clapping, the visiting teacher asks the class if there is anyone else who wants to volunteer to attempt to answer her question, and S2 simultaneously raises her hand. The simultaneity of the action shows that S2 knows that applause implicates closing and that the teacher is going to select the next student upon cessation of the applause. From the analysis of the sequential interaction, it is revealed that both the teacher and the student orient to the fact that applause is used to close a sequence in the class.

In summary, as seen from the analysis above, the applause in the data occurred at an activity or sequence closing position and does the action of sequence closing.

\section{Who initiates applause}

As noted above, the applause occurred in overlap with the teacher's production of "very good," "good," or "okay," in a sequence closing position. Furthermore, except in the qualifying case noted in Extract (4) below, it was almost always the teacher who initiated the applause. A further example of teacher initiation of applause is shown in the following extract from a lesson on the names of the days of the week.

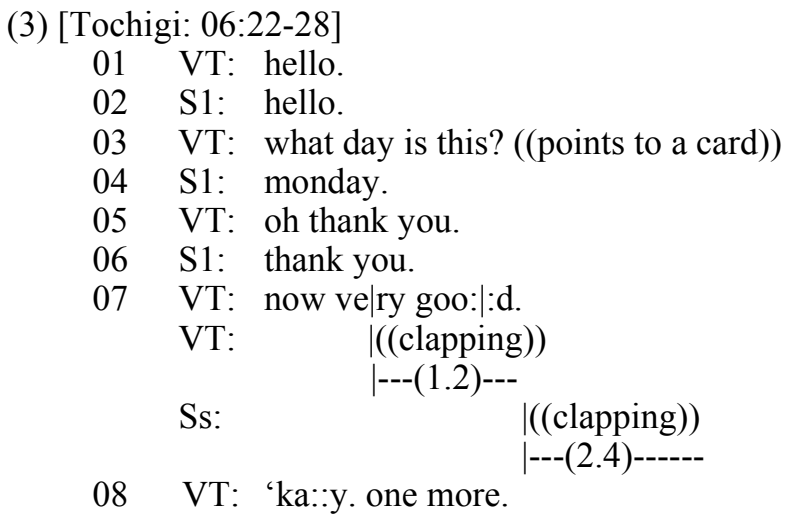

In Extract (3), S1, who was called on to demonstrate the dialog, is performing in front of the class with the visiting teacher. After a short greeting, the teacher points to a card with the name of a day of the week printed on it and asks, "what day is this?" The student then provides a correct response with "monday", the teacher thanks the student for participating, the student thanks the teacher, and the teacher praises the student by using the assessment token "now very goo::d" with a lengthened vowel on the final word. As the dialog ends with line 6, in line 7 the teacher, who had his gaze fixed on S1, looks at the whole class and initiates applause just after starting to produce "now very goo::d" as an assessment token. As soon as the teacher starts clapping, the students, except S1, start clapping. The applause continues for several seconds and then in line 8 the teacher calls for another student to demonstrate the same dialog.

Applause is usually seen as a collaborative activity that is accomplished in unison with others. Consequently, starting to applaud by oneself is considered to be embarrassing. If one finds that others are not applauding, the person applauding will terminate their applause after just a few claps (Heritage \& Greatbatch 1986). However, in the English classes analyzed in this data set, this convention does not always apply: the teachers can and do sometimes applaud by themselves. Consider again the interaction in Extract (1). In this extract, the teacher's applause in line 11 is not joined by any of the students or the homeroom teacher. Nevertheless, she continues applauding for more than 2 seconds. In comparison to audience applause in political speeches, 
which may last for up to 8 seconds, applause lasting only 2 seconds may be interpreted by the interactants as being rather short. Yet, length of applause varies depending on an event. In the present data from English as a foreign language classes, the average duration of applause was only 2 or 3 seconds. The brevity of this applause is not oriented to by any of the interactants as being out of the ordinary. Therefore, an applause duration of only 2 seconds is not noticeable as being short in this interactional context.

On the other hand, throughout the data, when the students in these classes found themselves applauding by themselves without initiation from the teacher, they stopped after little more than 1 second. Extract (4) is an example of a single student abandoning applause.

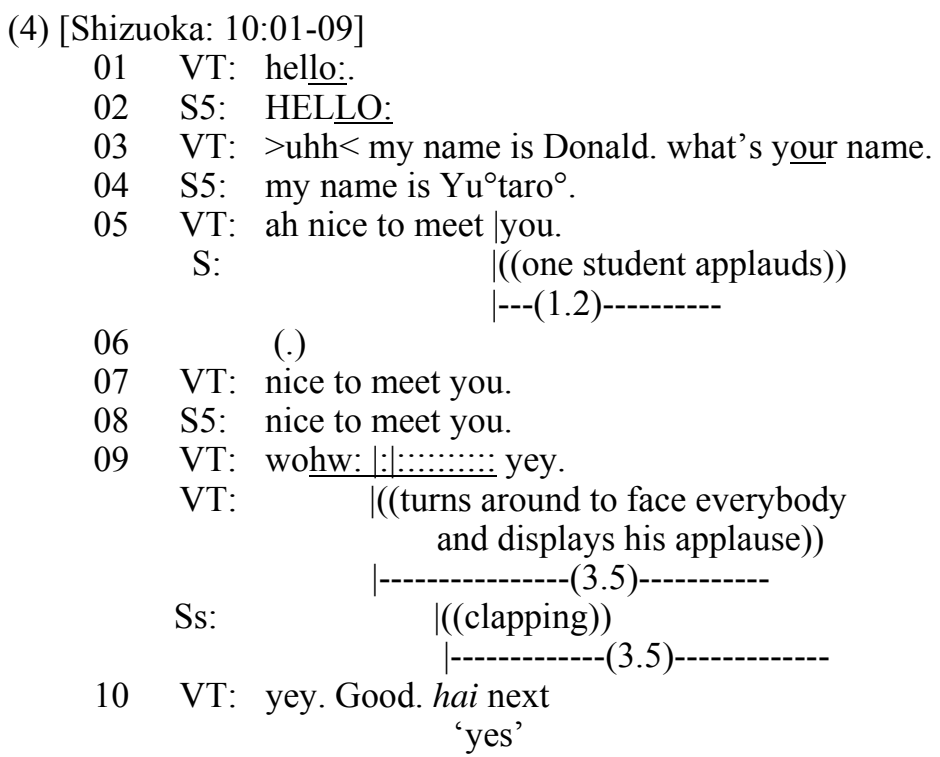

In Extract (4), a visiting teacher and a student, S5, are practicing a dialog in front of the entire class. In line 5, as the teacher is coming to the end of the greeting sequence phrase "nice to meet you.", one student begins to applaud. However, this students" applause is not joined by the other students, and so the student who started clapping terminates her applause after 1.2 seconds. Thereupon the teacher redoes the first pair part of the closing of the introduction by saying, "nice to meet you." By redoing the first pair part, the teacher sequentially deletes S's clapping and treats her clapping as an interruption. This time, however, none of the students initiate applause, and in line 8, S5 produces the second pair part of the adjacency pair, "nice to meet you.", thus completing the display dialog. Consequently, in line 9, while saying "wohw::::::::::::: yey.", the teacher launches into applause displayed to the whole class as he swings his body around away from his dialog partner and faces the rest of the class in order to invite their applause. The students, except S5, and the other teacher join this applause and the collective applause continues for about 3.5 seconds.

The extracts analyzed in this section have revealed that applause occurs at an activity or sequence terminating position and is initiated by the teacher. As seen in Extract (4), when one student attempted to initiate applause, the teacher's sequential deletion of the applause was observed. In the following section, the action of applause is exhibited through the teacher student interaction.

\section{Action of applause}


In previous research on applause (Atkinson 1984a, 1984b, 1985, 1986; Heritage \& Greatbatch 1986), the action of applause is understood as an affiliative response by the audience to rhetorical devices used by a public speaker. The prior section provided some analyses of where applause occurs and who initiates applause. In the next section we look at the action of applause in the language learning classroom.

\section{Applause as positive assessment of individual, pair, and group performance}

As noted in the previous section on occurrence of applause, in this data set the use of applause was invariably associated with sequence and activity closing. It was also demonstrated that the applause accompanied words and phrases of assessment such as "very good," "good," or "okay," and this combination of ["good," etc. + applause] occurred subsequent to some sort of student performance. These performances emerged from the data in three forms: as either (a) individual performance (teacher and one student), (b) pair performance (two students), or (c) group performance (whole class). Extract (5) is an example of teacher initiated applause following individual student performance. In this extract the visiting teacher and a student (S1) are performing a dialog in front of the class.

(5) [Fukushima: 01:35-02:07]

((S1 is asked a question by the visiting teacher.))

01 VT: hello.

02 S1: ${ }^{\circ}$ hello ${ }^{\circ}$

03 VT: h(h):i. h::i.

04 S1: ${ }^{\circ} \mathrm{hi}^{\circ}$

05 VT: okay. what day is it today. what day is it

06 today.

$07 \quad(0.5)$

08 VT: day day day.

09 S2: ${ }^{\circ}$ it's [monday ${ }^{\circ}$ ((to S1))

10 S1: [it's (.) monday.

11 VT: it's MONday. oh $|\mathrm{h}|$ kay that's good. yey.

VT: $\quad$ ((clapping))

Ss: $\quad \mid($ (clapping) $)$

12 VT: okay. h:i, ((The teacher greets the next student.))

After the teacher and S1 complete their greeting with exchanges of "hello" and "hi", the teacher opens the sequence with "okay.", and then twice asks the question, "what day is it today." The 0.5 second pause in line 7 indicates that the student's answer is slow in getting launched. Therefore, in line 8, in an apparent attempt to assist the student, the teacher emphasizes through repetition the key word in the sentence, "day", which the teacher, as evidenced by the repetition, seems to think the student has not understood. In line 9, S2, who is sitting in front of S1, turns around to face S2 and whispers the answer, "it's Monday", to S1. Then in line 10, just after S2 starts whispering the answer, S1, in overlap with S2, answers the teacher's question. The teacher evidences acceptance of the answer in line 11 by repeating it, adding extra stress on the first syllable of the key word, and saying "okay that's good. yey". After the repetition and just as he begins to say, "ohh kay", the teacher starts to applaud, which is then immediately taken up by the entire class (except S1).

Extract (6) is an example of pair performance followed by teacher applause. At this point in the lesson, two students are performing a dialog at the front of the class with the assistance of the visiting teacher. 
(6) [Nagano3:19:22-20:05]

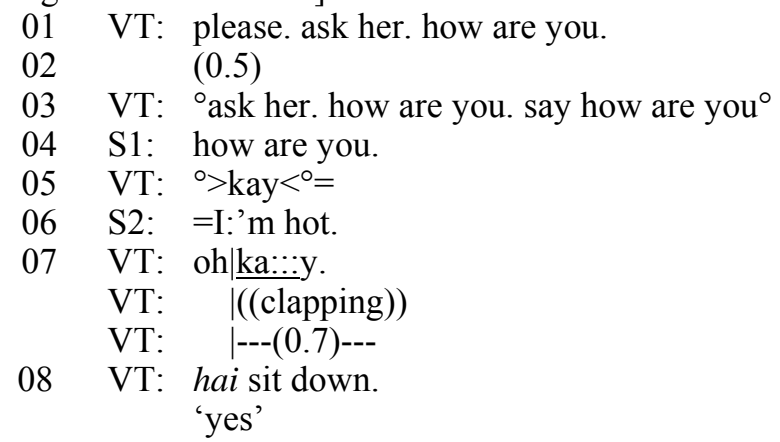

In line 1, the teacher prompts S1 to ask S2 the question, "how are you." However, as S1 does not follow the instruction, as indicated by the 0.5 second pause, in line 3 the teacher repeats the instruction, this time using quite voice, and employs an additional repetition with the directive to speak, "say how are you". Subsequently, in line 4, S1 looks at S2 and says "how are you." The teacher responds to this with a quickly, quietly, and abbreviatedly spoken "०>kay<o". S2 answers with, "I'm hot", and the teacher applauds after the first syllable of "ohka:::y".

The next extract, (7), is an example of group performance followed by applause. Extract (7) occurs after the class has finished playing a card game in small groups in which the students had to quickly grab the picture card of the word called out by the teacher. In the extract, the visiting teacher is asking how many cards each group collected during the game.

(7) [Nagano5: 36:13-19]

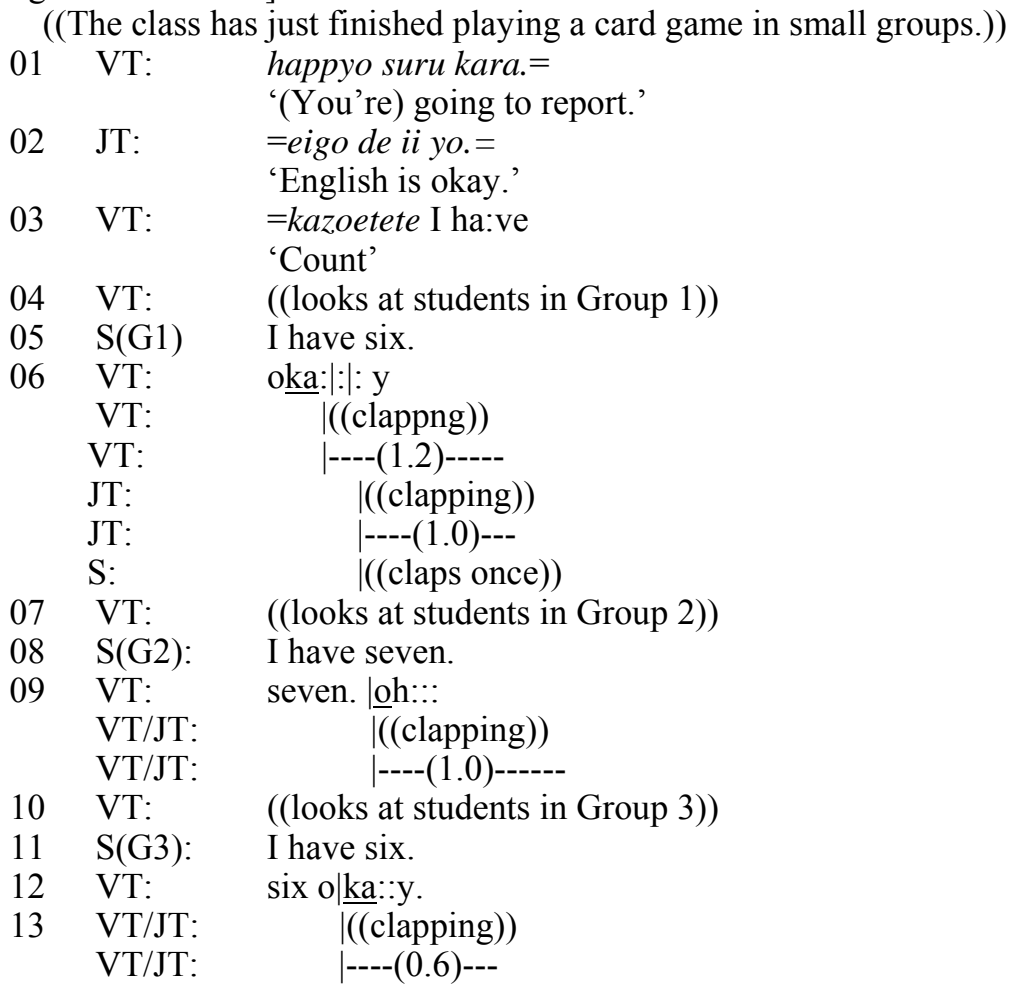

In line 3, the teacher explicitly instructs the students to answer by using the phrase, "I 
have ." and the number of cards. Although the phrase is in the singular, the representative is reporting the number of cards for the group. In lines 5 to 13, each time the student representative from a group presents their results, the teacher applauds.

In Extracts (5), (6), and (7), the combination of ["good" etc. + applause] occurs after student performance of a conversation activity arranged by the teacher. In Extract (5), the teacher and S1 model a question/answer dialog; applause occurs after they finish performing the dialog. In Extract (6), the teacher directs S1 to ask S2 the question, "how are you?" S2 responds with, "I'm hot," and the teacher applauds after the two students finish the exchange. In Extract (7), after a picture-card game, the teacher has each group report how many cards they have. The teacher applauds after the representative from each group reports the number of cards they have won in the game. The deployed combination ["good" etc. + applause] served as a multimodal positive assessment of the students' successful performance of the task as assigned by the teacher. It is "positive" in the sense that applause itself implicates affiliation and has a positive connotation. Moreover, after the combination ["good" etc. + applause], the sequence moves forward (that is, it moves to the next activity or student) without further expansion or interruption.

\section{Applause as positive evaluation of teacher's oriented-to expectations}

In conversational interaction, it has been noted that even when the speaker does not agree with what the prior speaker has said, the speaker frequently produces an agreement preface such as "yeah," "yes," or "uh huh," before producing a disagreement component (Davidson 1984; Pomerantz 1975, 1984; Sacks 1987). Similarly, in examining classroom interactions, Seedhouse (2001) found that teachers tend to avoid saying "no" as feedback to students' candidate responses, but as an alternative often produce acceptance tokens (e.g., "okay," "good") prior to repairing the students' productions. In our data also, even when the teacher did not accept the student's response, the teacher produced verbal acceptance tokens.

In the interaction analyzed here, students' responses that could be considered "appropriate" or "acceptable" outside the language learning classroom context did not always result in the teacher's use of the combination ["good" etc. + applause], but sometimes resulted in mere verbal assessments such as "good," "okay," and the like without applause. Consider the interaction in Extract (8) below.

(8)[Shizuoka:12:20-13:03]

((The teacher, VT, takes out an oval-shaped ball and shows it to the students. VT then selects $\mathrm{S} 11$ to answer his question.))

01 VT: what's this. you know?

02 (0.4) ((some Ss whisper "ragubii ball"))

03

04

(S11): ragubii ball

VT: $>\uparrow o h \downarrow[h<$

05 S11: [ragubii ball

06 VT: rugby ba:ll. oka:y. (1.0) in Canada, we say

07

08

(.) football. $>$ football but rugby ball. $<$ (.)

okay yeah.

In Extract (8), the teacher shows the students an oval-shaped child's ball and asks S11 to tell him what it is. In line 5, S11 answers, "ragubii ball" ("rugby ball"). S11's answer is linguistically appropriate since the oval shaped ball could certainly be seen as a rugby ball in other contexts. The teacher proceeds by repeating "rugby ball" and then saying "okay." in line 6. This "okay," however, is not accompanied by applause. Moreover, he adds an explanation with, "in Canada, we say (.) football.", which shows that "rugby ball" was not the response he was expecting, and that "football" was the answer he was 
attempting to elicit. Although he does initially and finally accept "rugby ball" as an answer, the micropause before football emphasizes the word football and demonstrates that the teacher is noting the, for him, more accurate term.

Similarly, in Extract (9), a student response which could very well be considered "correct" in contexts other than the classroom was not followed by applause. Prior to this extract, the teacher explained to the class that the student who is holding the card with the name on it that the class calls should stand up and say, "Yes, I am." As preparation for the activity, the teacher handed out one card to each student on which was written the name of a famous person.

(9) [Fukushima:14:14-20]

((The visiting teacher explained to the class that the student holding the card with the name on it that the class calls out should respond with, "Yes, I am."))

01 VT: Ian Thorpe? Ian Thorpe? oka:y. ohkay. ARE YOU

02 IAN THORPE?

03 Ss: are you Ian Thorpe?

$04 \quad$ (3.5) ((other Ss chatting))

05 S12: ${ }^{\circ}$ no I'm not ${ }^{\circ}$

06 VT: n(h)o I'm n(h)ot. ohhh. uh:. yes? n(h)o?

07 S12: no.

08 VT: no. ((covers his face with his hands)) okay.

In line 1 the teacher asks the question. "ARE YOU IAN THORPE?" The students then repeat the question in chorus in line 3. According to the teacher's directions for the activity, the student who is holding the "Ian Thorpe" card should immediately respond by standing up and saying, "yes, I am." Contrarily, following a long pause in line 4, in line 5, S12, who has the "Ian Thorpe" card, says "no I'm not ${ }^{\circ} . "$ Outside of the institutional setting of the language learning classroom, this would be a perfectly acceptable answer as the student's name is not Ian Thorpe. However, in response to S12's negative statement, the teacher, in line 6, repeats the student's answer, " $n(h) o$ I'm n(h)ot.", and utters, "ohhh. uh:." The teacher then checks with the student to see if that is really his answer, "yes? n(h)o?" In line 7, the student confirms his answer with the response, "no." And then in line 8, the teacher repeats "no," covering his face with his hands, which possibly indicates shock at the student's answer, and then accepts the student's answer by saying, "okay." This "okay" is not accompanied by applause.

As shown in Extracts (8) and (9), even when the students' contributions could be considered to be perfectly acceptable outside of the language learning classroom context, when they deviated from the oriented-to expectations of the teacher, the teacher did not applaud. "Oriented-to expectations," in this paper, refers to the structures of the activities that the teacher orients to in the interaction, and includes the teachers' communicated expectations of what student responses should be.

Also observed were instances in which the teacher delayed applauding when the students' production did not follow the teacher's oriented-to expectations. In Extract (10), the teacher withholds applause until the precise pattern of the dialog he envisaged is produced. During this language learning activity, the students are introducing themselves to each other using the identities of famous cartoon characters.

(10) [Shizuoka: 20:20-21:20]

((The teacher asks S18 and S19 to come to the front of the class to demonstrate the modeled dialog. In the extract, Anpanman and Mario are the names of famous animated characters in Japan.))

01 VT: OKAY. ready:? shh. hello.

02 S18: hello?

03 S19: hello.

04 VT: my name is, 


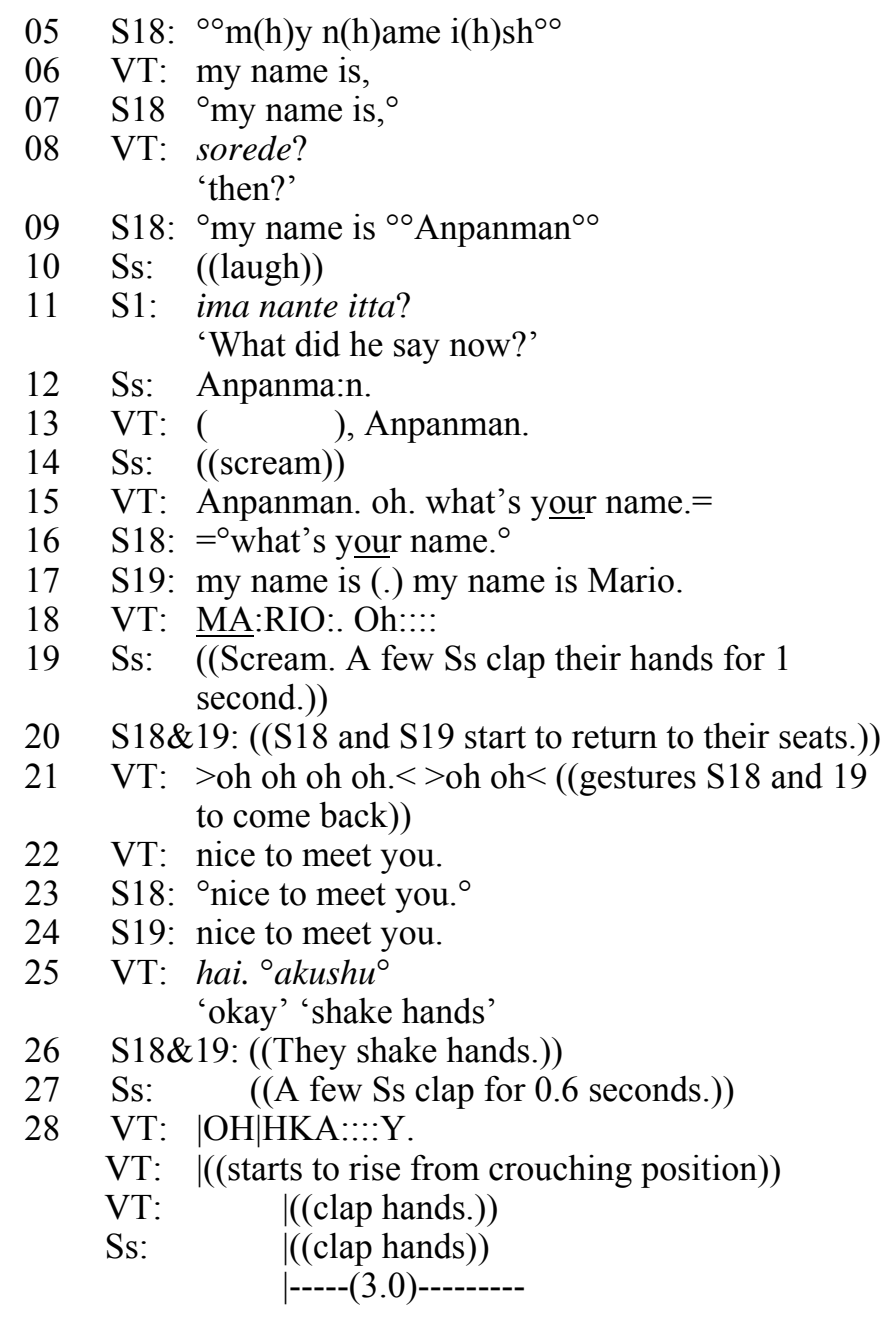

After the two students, S18 and S19, finish their dialog, in line 17, and the teacher repeats S19's pseudonym, they start to return to their seats while a few students start to applaud for three or four claps. However, the teacher gestures for the two students to come back to the front. Then he says, "nice to meet you." as a directive to repeat the line. When the students have said the phrase to each other, the teacher asks them in Japanese to shake hands. S18 and S19 shake hands as a gesture of introduction and the teacher produces an emphatic "OHHKA::::Y." This "OHHKA::::Y." is overlapped by applause from the teacher and the whole class (except S18 \& S19). The fact that the teacher recalled the students shows that his oriented-to expectations included not only having the students give their fictional names, but also having them say, "nice to meet you.", and shake hands. Therefore, until the complete sequence was carried out, the teacher refrained from giving both verbal assessment and applause. ${ }^{4}$

4 Teachers may produce the verbal tokens, "okay," "good," and the like, even when the students response is not exactly the same as their communicated expectations, but they tend to refrain from applauding until the student reponse matches their expectations. In addition to Extract (8), instances of the verbal token "okay" not being accompanied by applause can be observed in Extracts (5) and (6). In Extract (5), in line 5, the teacher's "okay" is not accompanied by applause and the teacher moves on to the next adjacency pair, a question and an answer. This shows that although the teacher accepts the appropriateness of S1's greeting, the teacher's displayed expectation is not only to exchange greetings with S1, but to ask S1 a question and to get an appropriate response for that question from S1. Therefore, 
In the preceding sections, it has been demonstrated that the teachers' oriented-to expectations are communicated through deployment of applause in the interaction. Interestingly, the teacher's communicated orientation was also manifested in the student's behavior. In Extract (11), one of the students displays his orientation to the teacher's oriented-to expectations by correcting the student who answered the teacher even after the teacher accepted that student's answer. The class is engaged in the same language learning activity as in Extract (9).

(11) [Fukushima:11:18-28]

((The same activity as Extract (9). The visiting teacher explained to the class that the student holding the card with the name on it that the class calls out should respond with, "Yes, I am."))

01 VT: oka:y. First one.

02 JT: hai.

'yes'

03 VT: Are you Jackie Chan? ((hearing gesture))

04 Ss: Are you Jackie Chan?

05 VT: oka:y

06 JT: Yes ((signals S1 to stand up))

07 S1: ((stands up))

08 Ss: ((some Ss)) \$Jackie Cha:n\$

09 JT: ${ }^{\circ}\left(>\right.$ kotae $\left.^{<}\right)$yess $^{\circ}$ I am 'answer'

10 S1: ((stand up)) I am Jackie Chan.

11 VT: oh $\uparrow$ h wokay o|kay I am $>$ Jackie Ch- $<$ okay

VT: $\quad$ ((clapping))

Ss\&JT: $\quad \mid($ (clapping))

12 S20: ((the boy in front of S1)) Yes I am da yo.=

'It should be yes I am.'

13 VT: =Yes I am. okay.

14 S1: ${ }^{\circ}$ Yes I am ${ }^{\circ}$ Jackie Chan=

15 VT: =oka::y yea::h goo::d. oooh Jackie Chan

16 Hhe:::w. okay let's see now number two::.

In line 10, in response to the choral display question, "are you Jackie Chan?", from the teacher and the other students, S1 answers, "I am Jackie Chan." The form of S1's answer is not exactly the same as what the teacher had earlier taught the students to use ("Yes, I am") as it does not include "Yes" and adds a repetition of the name. However, it might be acceptable in conversation outside the context of the language learning classroom. Though possibly not pragmatically correct in some situations, it is grammatically correct and possibly pragmatically correct in certain situations. The point here being that it is not the form that the teacher had asked the students to use for this activity. The teacher's production of the change of state token "oh $\uparrow$ " in line 11 indicates that S1's answer is something unexpected and not in the expected form. The teacher then accepts the answer saying "wokay," but he does not start applauding at this point. Only when he produces "okay" the second time does he start applauding, and then the other students join him in applauding. In the context of ordinary conversation, it has been found that positive responses occur immediately without a gap, whereas

it is only after S1 provides an appropriate response to the teacher's question that the teacher starts applauding. In Extract (6), the teacher's utterance " $>$ kay $<{ }^{\circ}$ " in line 5 is not accompanied by applause but "ohka:::y" in line 7 is. This allows us to see that the teacher's oriented-to expectation was not just to have one student say "how are you" but to have two students exchange the "how are you" "I'm " adjacency pair. 
negative responses are delayed, that is, often produced after a gap (Davidson 1984; Pomerantz 1975, 1984; Schegloff 2007). In the data analyzed here, the occurrence of the teachers' applause was often delayed when the students' responses did not match the teachers' expectations. Subsequently, even though the teacher has started applauding, S20, who is sitting in front of S1 and is not applauding, turns around to face S1 and says, "yes I am da yo.", which means "You are supposed to say, 'Yes I am."” In other words, S20 orients to the precise linguistic form, "Yes, I am.", that the teacher introduced at the beginning of the activity, and he seems to consider S1's answer, "I am Jackie Chan", to be inappropriate and in need of repair. As this example demonstrates, the orientation to the teacher's communicated expectations was displayed not only in the teacher's behavior but also in the students' behavior.

\section{Conclusion}

In this paper, we have demonstrated that applause in Japanese primary school EFL classes is a teacher-initiated action that regularly occurs in sequence closing positions as a positive assessment of one or more students' performance. The examination of non-occurrence and delayed cases of applause shows that the teacher used applause as a positive assessment of those students who successfully implemented the teacher's oriented-to expectations. Furthermore, observation of non occurrence and delayed cases revealed the following points.

First, mere verbal assessment and the combination of verbal assessment and applause have different connotations in the interaction. As the present data show, the teacher's verbal assessments, "good", "okay", and the like, occur even when the answer the student or students provide is not exactly the same as what the teacher expects, while the combination of applause and verbal assessment occur only when the students' answers match the teacher's oriented-to expectations. Thus applause may be a higher level of approval than mere verbal assessment as it functions to indicate that the response given was appropriate for the teacher's oriented-to expectation. Moreover, as applause is more of a public activity than mere verbal assessment as it invites everybody to join in the action of approval, the teacher's action demonstrates to all students the expected participation norms for classroom interaction.

Second, the data show that even when the students' contributions were acceptable in form for contexts other than the classroom, the teacher refrained from applauding when the students' contributions deviated even slightly from the teacher's displayed orientation. Therefore, although the teacher's task-as-workplan, as displayed in their orientations, and the actual development of the task tend to differ (Breen 1989), in the culture of the classroom, how accurately the students demonstrate the teacher's expected linguistic forms or patterns of interaction may be more important than how effectively the students actually communicate in the second language. ${ }^{5}$ The orientation to this classroom culture is shown not only in the teacher's behavior but also in the students' behavior as the students try to design the form of their response to match the teacher's oriented-to expectations.

This paper demonstrates that applause functions in classroom interaction at a higher level than verbal assessment to indicate agreement with the teacher's oriented-to expectations, and exhibits the cultural norm of the language learning classroom that focuses on the teacher's exhibited frame rather than achievement of communicative success. Therefore, teachers' norms supersede natural norms of communicative success in language use, and may cause learners to adjust too much to what the teacher pursues. Thus, it is essential for teachers to provide time for familiarizing learners with natural language in the classroom, rather than always pursuing only the specific words, phrases,

5 This point is also shown in Seedhouse $(2001,2004)$. Seedhouse demonstrated how the teachers repair the students' responses when the students' responses do not match the teachers' expectations. 
and dialogs they have oriented to. Furthermore, the findings highlight the importance of including in analysis not only verbal actions but also non-verbal actions as non-verbal actions not only interact with but may actually override verbal actions. Consequently, future research on classroom interaction should not exclude a priori nonverbal actions but should examine the whole ensemble of language and bodily behaviors.

\section{References}

Atkinson, J.M. (1984a) Our Masters' Voices. The Language and Body Language of Politics. New York: Methuen.

Atkinson, J.M. (1984b) Public speaking and audience responses: Some techniques for inviting applause. In J.M. Atkinson \& J. Heritage (eds.), Structures of Social Action: Studies in Conversation Analysis. Cambridge: Cambridge University Press, pp. 370-409.

Atkinson, J.M. (1985) Refusing invited applause: Preliminary observations from A case study of charismatic oratory. In T. van Dijk (ed.), Handbook of Discourse Analysis, Vol. 3, Discourse and Dialogue. London: Academic Press, pp. 161-181.

Atkinson, J.M. (1986) The 1983 election and demise of live oratory. In I. Crewe and M. Harrop (eds.), Political Communications: The General Election Campaign of 1983. Cambridge: Cambridge University Press, pp. 38-55.

Breen, M. (1989) The evaluation cycle for language learning tasks. In R.K. Johnson (ed.), The Second Language Curriculum. Cambridge: Cambridge University Press, pp. 187-206.

Davidson, J. (1984) Subsequent versions of invitations, offers, requests, and proposals dealing with potential or actual rejection. In J.M. Atkinson \& J. Heritage (eds), Structures of Social Action: Studies in Conversation Analysis. Cambridge: Cambridge University Press, pp. 102-128.

Goodwin, C. (1986) Between and within: Alternative sequential treatments of continuers and assessments. Human Studies 9: 205-217.

Heritage, J., and D. Greatbatch (1986) Generating applause: A study of rhetoric and response at party political conferences. American Journal of Sociology 92.1: 110-157.

Jefferson, G.. (1984) On the organization of laughter in talk and troubles. In J.M. Atkinson \& J. Heritage (eds.), Structures of Social Action: Studies in Conversation Analysis. Cambridge: Cambridge University Press, pp. 346-369.

Jefferson, G. (1985) An exercise in the transcription and analysis of laughter. In T. van Dijk (ed.), Handbook of Discourse Analysis, Vol. 3, Discourse and Dialogue. London: Academic Press, pp. 25-34.

Jefferson, G.., H. Sacks, \& E.A. Schegloff (1987) Notes on laughter in pursuit of intimacy. In G. Button and J.R.E. Lee (eds.), Talk and Social Organization. Clevedon: Multilingual Matters, pp. 152-205.

Pomerantz, A. (1975) Second assessments: A study of some features of agreements/disagreements. Ph.D. dissertation. University of California, Irvine.

Pomerantz, A. (1984) Agreeing and disagreeing with assessments: Some features of preferred/dispreferred turn shapes In J.M. Atkinson \& J. Heritage (eds.), Structures of Social Action: Studies in Conversation Analysis. Cambridge: Cambridge University Press, pp. 57-101. 
Sacks, H. (1984) Notes on methodology. In J.M. Atkinson \& J. Heritage (eds.), Structures of Social Action: Studies in Conversation Analysis. Cambridge: Cambridge University Press, pp. 21-27.

Sacks, H. (1987) The preferences for agreement and contiguity. In G. Button and J.R.E. Lee (eds.), Talk and Social Organisation. Clevedon: Multilingual Matters, pp. 54-69.

Sacks, H., E.A. Schegloff, \& G. Jefferson (1974) A simplest systematics for the organization of turn-taking for conversation. Language 50: 696-735.

Schegloff, E.A. (2007) Sequential Organization in Interaction: A Primer in Conversation Analysis 1. Cambridge: Cambridge University Press.

Seedhouse, P. (2001) The case of missing "no": The relationship between pedagogy and interaction. In R. Ellis (ed.), Form-focused Instruction and Second Language Learning. Malden, MA: Blackwell, pp. 347-385

Seedhouse, P. (2004) The Interactional Architecture of the Language Classroom: A Conversation Analysis Perspective. Malden, MA: Blackwell.

\section{Appendix}

\section{Transcription Conventions}

\begin{tabular}{|c|c|}
\hline ] & overlapping talk \\
\hline $\mid$ & overlapping of nonverbal behavior \\
\hline$=$ & $\begin{array}{l}\text { continuation of nonverbal feature } \\
\text { latched utterances }\end{array}$ \\
\hline .0$)$ & timed pause (in seconds) \\
\hline & a short pause \\
\hline :lon & extension of the sound or syllable \\
\hline ::lon & $\begin{array}{l}\text { a more prolonged stretch } \\
\text { fall in intonation (final) }\end{array}$ \\
\hline & continuing intonation (non-final) \\
\hline ? & rising intonation (final) \\
\hline APITAL & loud talk \\
\hline derline & emphasis \\
\hline$\uparrow$ & sharp rise \\
\hline$\circ$ & sharp fall \\
\hline$\$$ & smiley voice \\
\hline$>$ & slow talk \\
\hline$<$ & fast talk \\
\hline & audible aspirations \\
\hline & laughter within a word \\
\hline )) & comment by the transcriber \\
\hline ) & $\begin{array}{l}\text { problematic hearing that the transcriber is not } \\
\text { certain about }\end{array}$ \\
\hline “ & Idiomatic translation of Japanese utterances \\
\hline
\end{tabular}


DAVID ALINE earned his EdD from Temple University in 1999 and is a professor at Kanagawa University, Yokohama, Faculty of Foreign Languages, Department of Cross-Cultural Studies, and teaches psycholinguistics in the Graduate School of Foreign Languages. His research interests include second language acquisition and use in university, primary school, lingua franca, and tutorial settings through a conversation analytic perspective.

Address: Faculty of Foreign Languages, Kanagawa University, 3-27-1 Rokkakubashi, Kanagawa-ku, Yokohama 221-8686, Japan. Tel.: 81-45-481-5661; Fax: 81-45-491-7915; e-mail:

alined01@kanagawa-u.ac.jp

YURI HOSODA received her EdD from Temple University in 2002 and is currently an associate professor in the Faculty of Foreign Languages, Department of Cross-Cultural Studies, and the Graduate School of Foreign Languages at Kanagawa University, Yokohama. Her research examines second language use and learning in Japanese and English at university, primary school, work place, and mundane conversation through a conversation analytic perspective.

Address: Faculty of Foreign Languages, Kanagawa University, 3-27-481-5661; fax: 81-45-491-7915; e-mail: yhosoda@kanagawa-u.ac.jp 